\title{
QUAIS LUTAS SINDICAIS SÃO POSSÍVEIS CONTRA OS DA- NOS À SAÚDE DOS TRABALHADORES QUALIFICADOS?
}

\author{
WHAT UNION STRUGGLES ARE POSSIBLE AGAINST \\ HEALTH DAMAGE OF QUALIFIED WORKERS? \\ QUELLES LUTTES SYNDICALES POSSIBLES CONTRE \\ LES ATTEINTES À LA SANTÉ DES TRAVAILLEURS QUALIFIÉS? \\ ¿QUÉ LUTAS SINDICALES SON POSIBLES CONTRA \\ LOS DAÑOS A LA SALUD DE LOS TRABALHADORES CUALIFICADOS?
}

Lucie Goussard*

RESUMO: Nos últimos quinze anos, a saúde no trabalho tem recebido atenção constante no debate social francês, particularmente após a cobertura da mídia sobre suicídios que ocorreram em grandes empresas como Renault, EDF, France Telecom e La Poste. Neste contexto, os atores sindicais são mais do que nunca interpelados sobre estas questões: eles não são apenas levados a negociar acordos sobre o tema, a debater nas instâncias representativas das categorias profissionais e a construir ações dentro de suas próprias organizações, mas também são chamados a responder, em um nível mais local, às crescentes demandas dos trabalhadores que enfrentam problemas de saúde relacionados ao seu trabalho. Este artigo propõe-se a examinar suas ações nessa área, com base em uma pesquisa realizada desde $2012 \mathrm{em}$ um centro de pesquisa industrial. Para dar conta de sua história, suas práticas e experiências, são mobilizadas cerca de vinte entrevistas com representantes dos trabalhadores pertencentes a várias organizações, uma dúzia de entrevistas com membros da equipe de direção, médicos do trabalho, membros de departamentos de $\mathrm{RH}$, funcionários e observações diretas das reuniões do Comitê de Empresa (CE).

Palavras chave: Sindicalismo; Saúde no trabalho; Lutas sindicais; Ativismo; Instâncias representativas da categoria profissional.

ABSTRACT: For the past fifteen years, health at work has received sustained attention in the French social debate, particularly following the media coverage of suicides that have occurred in large companies such as Renault, EDF, France Telecom and La Poste. In this context, trade union actors are more than ever expected on these

\footnotetext{
* Doutora em Sociologia; Mestre de Conferência em Sociologia, Universidade de Évry, Paris Saclay, Centro Pierre Naville (CPN), Évry, França; E-mail: E-mail: goussard.lucie@gmail.com
} 
issues: they have to negotiate agreements on the subject, to debate in the representative bodies of staff and to build actions within their own organizations but also to respond, at a more local level, to the increasing demands of employees who encounter health problems related to their work. This article proposes to examine their actions in this area, based on a survey conducted since 2012 in an industrial research center. To give an account of their history, their practices and experiences, it will mobilize about twenty interviews with union activists belonging to various organizations, a dozen interviews with members of the management team, with occupational physicians, members of HR departments, employees, and direct observations of meetings of the Establishment Committee (EC).

Keywords: Trade unionism; Health at work; Union struggles; Activism; Representative bodies of staff.

RÉSUMÉ: Depuis une quinzaine d'années, la santé au travail bénéficie d'une attention soutenue dans le débat social français, notamment suite à la médiatisation des suicides qui se sont produits dans de grandes entreprises comme Renault, EDF, France Télécom et La Poste. Dans ce contexte, les acteurs syndicaux sont plus que jamais attendus sur ces questions: ils sont non seulement amenés à négocier des accords sur le sujet, à en débattre au sein des instances représentatives du personnel, à construire des actions au sein de leurs propres organisations, mais aussi à répondre, au niveau plus local, aux sollicitations toujours plus nombreuses des salariés qui rencontrent des problèmes de santé liés à leur travail. Cet article propose d'examiner leurs actions en la matière, à partir d'une enquête menée depuis 2012 dans un centre de recherche industrielle. Pour rendre compte de leur histoire, leurs pratiques et expériences, il mobilisera une vingtaine d'entretiens avec des représentants du personnel appartenant à diverses organisations syndicales, une dizaine d'entretiens avec des membres de l'équipe de direction, avec des médecins du travail, des membres des services $R H$, des salariés, et des observations directes de réunions du Comité d'Etablissement (CE).

Mots-clés: Syndicalisme; Santé au travail; Luttes syndicales; Militantisme; Instances représentatives du personnel.

RESUMEN: En los últimos quince años, la salud en el trabajo ha recibido atención constante en el debate social francés, particularmente tras la cobertura de los medios sobre suicidios que ocurrieron en grandes empresas como Renault, EDF, France Telecom y La Poste. En este contexto, los actores sindicales son más que nunca interpelados sobre estas cuestiones: no sólo se llevan a negociar acuerdos sobre el tema, a debatir en las instancias representativas de las categorías profesionales ya construir acciones dentro de sus 
propias organizaciones, pero también se les llama a responder, en un nivel más local, a las crecientes demandas de los trabajadores que enfrentan problemas de salud relacionados a su trabajo. Este artículo se propone examinar sus acciones en esta área, con base en una encuesta realizada desde 2012 en un centro de investigación industrial. Para dar cuenta de su historia, sus prácticas y experiencias, va a movilizar cerca de veinte entrevistas con representantes de los trabajadores pertenecientes a varias organizaciones, una docena de entrevistas con miembros del equipo de dirección, con médicos del trabajo, miembros de departamentos de RRHH, funcionarios y observaciones directas de las reuniones del Comité de Establecimiento (CE).

Palabras clave: Sindicalismo; Salud en el trabajo; Luchas sindicales; Activismo; Instancias representativas de la categoría profesional.

\section{INTRODUÇÃO'}

Em 2006, a revista Actes de la Recherche en Sciences Sociales publicou um dossiê intitulado "Saúde e Trabalho: Negação, Visibilidade, Medida”. Se os autores desta edição insistiam firmemente na negação das penas do trabalho, M. Gollac e S. Volkoff (2006) apontavam, na conclusão de seu artigo, vários incitadores suscetíveis de dar visibilidade às violações feitas à saúde dos trabalhadores: o crescente interesse da União Europeia e do Estado Francês por esta temática, sua midiatização crescente e o desenvolvimento de dados científicos sobre sua origem profissional.

Pouco mais de uma década após esta publicação, o assunto tomou proporções cada vez maiores nos debates políticos, midiáticos e científicos. Tal exposição fez recuar a negação dos agravosno mundo do trabalho? Observamos um reposicionamento dos assalariados, de seus representantes e de seus empregadores sobre estas questões? Uma desestabilização dos paradigmas sanitários e individualizantes até então dominantes sobre o tema (Clot, 2012)? Uma inflexão do "diálogo social" nas instâncias dedicadas a estas questões? Identificamos, nas empresas, novas maneiras de prevenir e conter os riscos profissionais? Um contexto mais favorável à emergência de lutas sindicais dedicadas ao tema?

1 Agradecemos à Sofia Salvatori pela tradução do artigo do francês para o português e à Leonardo Gomes Mello e Silva da Universidade de São Paulo (USP) pela sua releitura e preciosas sugestões. 
Para tentar responder a este questionamento, as análises aqui apresentadas se apoiarão sobre uma pesquisa feita entre 2012 e 2017 em um centro de pesquisa industrial, onde as equipes sindicais buscam constituir uma perícia alternativa ao discurso patronal em matéria de saúde no trabalho para mobilizar os assalariados e tentar iniciar lutas locais sobre estas questões. Para dar conta de sua história, suas práticas e experiências, o artigo lançará mão de cerca de 20 entrevistas com representantes de categorias profissionais pertencentes a diversas organizações (Solidaires Unitaires Démocratiques (SUD); Confédération Générale du Travail (CGT); Confédération Française de l'Encadrement - Confédération Générale des Cadres (CFE-CGC), dos executivos; Confédération Française Démocratique du Travail (CFDT), além de uma dezena de entrevistas com membros da diretoria, médicos do trabalho, membros do RH, empregados, e observações diretas de reuniões do Comitê de Empresa (CE) durante as quais as questões de organização e saúde no trabalho foram debatidas. Estes dados foram recolhidos durante três estudos realizados a pedido da comissão intersindical de rastreamento dos riscos psicossociais (RPS), pertencente ao CE deste centro. Outros materiais coletados durante tais pesquisas não serão abordados aqui.

$\mathrm{O}$ artigo vai, primeiramente, debruçar-se sobre a construção progressiva da penibilidade no trabalho como ação sindical no cerne deste centro de pesquisa (1). Vamos examinar em seguida como foram construídas, no espaço de alguns anos, as concepções ativistas sobre a temática (2). Enfim, vamos esclarecer as ações ativistas realizadas em nome da proteção da saúde dos trabalhadores para identificar tanto seus estímulos quanto seus obstáculos (3).

\section{A EMERGÊNCIA IMPROVÁVEL DA SAÚDE NO TRABA- LHO COM AÇÃO SINDICAL EM UM CENTRO DE PESQUI- SA E DESENVOLVIMENTO.}

Esta primeira parte visa retratar a construção progressiva da saúde no trabalho enquanto ação sindical no espaço profissional, em contraponto à representação dominante de trabalho penoso (1.1.). Sem 
negar os efeitos da midiatização do fenômeno e do trabalho de sensibilização dos ativistas impulsionado pelas centrais sindicais, veremos que no momento em que este centro de pesquisa se torna objeto de importantes reestruturações produtivas (1.2.), as equipes sindicais constatam que são cada vez mais solicitadas por empregados em situação de mal-estar no trabalho. Ainda que discreta e marcada por reservas por parte de numerosos executivos que se recusavam a publicizar sua situação, este aumento de testemunhos constitui um momento chave na estruturação de suas ações sobre o tema (1.3.).

\subsection{Um mundo profissional na contracorrente da representação dominante do trabalho penoso.}

A vergonha de protestar ou de reclamar de seu trabalho quando muitos são privados de trabalho, estando em situação de desemprego de massa e de progressão de empregos precários, é conhecida no mundo do mercado de trabalho (Dejours, 1998). No entanto, encontra eco particularmente no centro de pesquisa estudado, tendo em vista as condições de emprego e de trabalho dos assalariados que o compõem. Em muitos aspectos, seu universo profissional contrasta claramente com a concepção dominante de trabalho penoso, normalmente associada a atividades masculinas no meio industrial e técnico (Fortino, 2014), ao trabalho de execução, pouco qualificado, rotineiro, repetitivo, submisso a horários atípicos, ao status de emprego precário e com rendimentos mais baixos.

Em contraponto a esta realidade, os trabalhadores estudados transitam entre serviços dedicados à pesquisa industrial de um grande grupo francês, atividade que muitos consideram interessante e valorosa. Dotados de uma formação técnica de alto nível, $81 \%$ deles são diplomados em escolas de engenharia, titulares de um diploma universitário de nível Bac+5 (cursos universitários com duração mínima de 5 anos) $)^{2}$, ou até mesmo um doutorado, acumulando por vezes os títulos de engenheiro e doutor ${ }^{3}$. Seu salário atinge em média 5.794,00 euros (valor bruto) por mês, em 2011, fora prêmios - o que se aproxima dos 
rendimentos de um professor das universidades de ponta ${ }^{4}$.

Notemos igualmente que $97 \%$ destes profissionais estão em contrato com duração indeterminada $(\mathrm{CDI})^{5}$. Estas condições de emprego particularmente favoráveis reforçam, desta maneira, a tendência que a maioria destes assalariados têm de se verem como privilegiados, não podendo, por uma questão de lógica, reclamar de sua situação em comparação com outras categorias profissionais, desempregados e precários, que se apresentam muito mais desfavorecidos.

No que se refere ao meio de trabalho, exercem suas atividades como a maioria dos executivos (Flocco, 2015), dentro de imóveis de formas modernas que se apresentam luminosos e estimulam o convívio. No momento da pesquisa, ninguém trabalhava em open space. Os gestores e os peritos técnicos dispõem de salas individuais, enquanto que as outras categorias de profissionais dividem seus espaços com um ou dois colegas. Seus escritórios são quase que sistematicamente equipados com grandes paredes envidraçadas, oferecendo uma boa visão sobre as paisagens do centro de pesquisas. As salas de descanso são decoradas, contam com máquinas de bebidas gratuitas, poltronas e sofás confortáveis. As características deste ambiente levam, assim, os profissionais a pensarem que seria "indecente" ou "inconveniente" de se identificarem como trabalhadores com problemas de saúde no trabalho, como indica Marie, uma engenheira: "Aqui, não temos porque nos queixar: trabalhamos num ambiente agradável, temos espaços para almoçar na rua quando o tempo está bom, temos escritórios espaçosos. Nem trabalhamos em open space!".

A ideia segundo a qual não é socialmente aceitável que estes trabalhadores reclamem de suas condições de trabalho se alimenta, também, do discurso de certos gestores, médicos do trabalho ou conselheiros de recursos humanos, que tendem a amenizar as crueldades da atividade de pesquisa e desenvolvimento, preferindo por exemplo os termos "dificuldade de gestão de tarefas" ou "frustração" aos termos "mal estar" ou "sofrimento" para designá-los, como diz um médico do trabalho:

4 Segundo a tabela indicativa da função pública do Estado Francês.

5 Os trabalhadores não estatutários são essencialmente estagiários, doutorandos em regime da convenção industrial de formação em pesquisa (contrato CIFRE) e pós-doutorandos. 
"Não falo de mal-estar. Acho que seria exagerado. São dificuldades de gestão de tarefas, frustração, mas não mal-estar. É preciso ser honesto e olhar um pouco ao nosso redor. O sofrimento, não está aqui, está em outros lugares, nas cadeias de produção. Lá sim, há mal-estar, mas aqui, não!' (Médico do trabalho).

Este relativismo é por vezes defendido até por representantes da categoria profissional, inclusive entre os mais combativos sobre $\mathrm{o}$ assunto.

"Não estamos também na situação da Renault ou da France Télécom. Aconteceram suicídios na nossa empresa, mas na produção, não entre nossos pesquisadores. Ainda estamos relativamente protegidos aqui. Na produção, lá, é assustador. Nos call centers também, é uma verdadeira catástrofe." (Representante da categoria, CGT).

Apesar da opacidade do fenômeno, os riscos profissionais tomam uma extensão sem precedentes nas reivindicações dos ativistas do centro de pesquisa durante os anos 2000. Como poderemos ver, este período foi marcado por reestruturações de produção, originando profundas mudanças na atividade dos empregados.

\subsection{Um centro de pesquisa num contexto de reestruturações de produção}

Em um contexto de desregulamentação de seu setor de atividade, este antigo estabelecimento público nacional de caráter industrial e comercial, muda de status jurídico em 2004 para transformar-se em sociedade anônima de capital público, permitindo a abertura de seu capital e sua colocação na Bolsa. Ao mesmo tempo, e no centro do movimento de "modernização" das empresas públicas, esta empresa passa por transformações organizacionais (Tixier, Mauchamp, 2000; Tixier, 2002; Boussard, Martin, Vézinat, 2015), em nome da otimização de seus meios, do relaxamento de seu funcionamento hierárquico e de uma maior atenção para as necessidades dos usuários. 
No setor Pesquisa desta empresa, o objetivo passa pelo reforço da logística de projeto, iniciada nos anos 1980. O organograma "vertical" que prevalecia até então, desapareceu em benefício de uma organização de matriz, que acrescenta à estrutura vertical, composta por grupos e departamentos, uma linha horizontal de condução das atividades, encarregada de gerenciar as relações com os clientes, administrar os recursos financeiros e assegurar a continuação dos projetos para os quais os pesquisadores estão nomeados. Este organograma bidimensional coloca, assim, cada um deles sob a direção de no mínimo dois superiores, um chefe de projeto e um chefe de equipe, e pertence, além da equipe de trabalho de sua "profissão original", a uma ou mais equipes de projetos pluridisciplinares e temporários. Longe de ser neutra, esta reorganização traz consigo orientações políticas (Boussard, Maugeri, 2003) que testemunham o aumento do poder dos financiadores em relação à orientação das atividades desta unidade de pesquisa (Goussard, Tiffon, 2013).

Esta reforma repousa igualmente sobre a vontade de substituir os pesquisadores e sua maneira de trabalhar para que sejam não somente "mais exigentes em matéria de respeito das metas" (diretor de Projeto), mas "mais voltados para as necessidades industriais da empresa" (membro da equipe de direção do centro de pesquisa). Encontramos aqui a lógica do financiamento para projetos empregada na pesquisa acadêmica, que "reforça a imposição do resultado" pela ativação de um "mecanismo de autocontrole" dos cientistas em relação aos compromissos acordados com seus financiadores (Barrier, 2011) e os aproxima das lógicas do gerenciamento e do mercado (Hackett, 1990; Jouvenet, 2011).

Com sua implantação, estas transformações organizacionais introduzem profundas mudanças na atividade dos empregados da direção de Pesquisa e Desenvolvimento (Goussard, Tiffon, 2013): os projetos sobre os quais trabalham são cada vez mais a curto prazo e operacionais. Ou seja, dedicam cada vez mais tempo à montagem do projeto em si, à busca por financiamentos e à constituição das equipes e não trabalham mais com apenas um projeto de cada vez, mas três ou quatro ao mesmo tempo, às vezes até cinco ou seis ao mesmo 
tempo. Este modelo de trabalho de multiprojetos, que consiste em administrar diversas atividades paralelamente, passando quase que cotidianamente de uma à outra, provoca numerosas solicitações e interrupções frequentes. Ora, esta "dispersão no trabalho" (Datchary, 2011) entra em conflito com a longa temporalidade, a concentração necessária à análise dos dados, à leitura e redação de documentos científicos, atividades que os empregados se consideram cada vez menos aptos a realizar no escritório, ocasionando um apelo freqüente à prática do "trabalho extra a domicílio" (Goussard, Tiffon, 2016). Combinadas, estas transformações alteram tanto as modalidades de reconhecimento destes trabalhadores (Goussard, Tiffon, 2017a) quanto os meios - financeiros e temporais - de que estes dispõem para realizar um trabalho de qualidade, o que reconhecemos como fonte de sofrimento (Clot, 2010).

\subsection{O aumento silencioso/discreto das manifestações de mal-es- tar junto às equipes sindicais}

Neste contexto de reestruturações de produção, as equipes sindicais constatam uma progressão do número de trabalhadores em sofrimento ${ }^{6}$, que reclamam de suas experiências e desapontamentos em seus locais de trabalho. "Antes, era uma, duas, três, quatro pessoas que vinham até nós por causa deste tipo de dificuldade. Agora, é mais de um, dois, três, quatro casos por mês que devemos gerenciar", declara um pesquisador delegado de base da CGT, lotado junto ao $\mathrm{CHSCT}^{7}$. Outros ativistas insistem no diagnóstico estabelecido pelos médicos do trabalho para reforçar esta constatação.

"Faz 21 anos que estou nesta empresa. Estou convencido de que as coisas pioraram. Sentimos isso claramente em relação ao nosso trabalho e já existem fatos objetivos para provarmos esse agravamento. Já na nossa categoria, temos cada vez mais alertas do tipo RPS [ris-

6 Tal diagnóstico junta-se ao diagnóstico estabelecido por outras equipes de ativistas, especialmente nos sindicatos SUD (Beynel, 2017) e CGT (Fortino, 2017).

7 Comité d'Hygiène, de Sécurité et des Conditions du Travail, equivalente à nossa CIPA (Comissão Interna de Prevenção de Acidentes). Na França, a comissão está prevista para empresas com mais de 50 funcionários. (N.d.R.) 
cos psicossociais]. E se você for ver, os médicos do trabalho dispõem atualmente de metodologias precisas para seguir esta evolução e há anos vemos claramente aparecer em seus relatórios casos de problemas psicossociais, problemas de sono, reações emocionais, depressões que estão ligadas ao trabalho. Percebemos isso. É indiscutivel que este fenômeno está crescendo, identificamos esse crescimento enquanto representantes da categoria e possuimos fatores objetivos para mensurá-los." (Representante eleito do CE, SUD).

Estas solicitações passam por diferentes canais: alguns trabalhadores batem diretamente na porta das sedes sindicais, outros são orientados pelo serviço médico, enquanto outros são identificados por colegas preocupados ao verem seu estado de saúde piorar, testemunhas de um mal-estar no local de trabalho, de um conflito que se tornou violento ou de uma crise de angústia. Uma vez estabelecido contato, a demanda encaminhada ao representante sindical varia de um trabalhador a outro. Se alguns solicitam uma intervenção das equipes sindicais junto aos seus superiores, do CHST ou dos serviços de recursos humanos, nem todos desejam tornar pública sua situação. Para eles trata-se de pôr em palavras um sofrimento doloroso, de tentar compreendê-lo, encontrar escuta, encontrar apoio.

Além dos pedidos individuais, os delegados observam que muitos de seus colegas queixam-se diariamente de seu trabalho sem, no entanto, revelar sua situação a seus superiores. É o que um deles chama de "expressão difusa do sofrimento":

"Sim, tem gente que vem nos ver. Mas o mais freqüente é a expressão difusa do sofrimento, que não vai manifestar-se de maneira individual, mas quase 24 horas por dia, junto à máquina de café, no momento da pausa para o almoço, entre duas reuniões, nos corredores, quando todos resolvem criticar a organização do trabalho. Assim, nestes casos, não é alguém que te procura pra dizer "não estou bem, vou arrumar um atestado, estou ficando louco". É todos os dias, uma espécie de ruido de fundo de um sofrimento, de um mal-estar que se expressa quando conversamos entre colegas, 
que escutamos coisas do tipo "me pediram coisas que não fazem sentido", "não consigo dar conta da minha tonelada de e-mails", "não dá mais, não consegui atingir minha meta", "não consigo dar conta", "dormi mal de novo", "estou perdendo o chão"... Isso sim, é o sofrimento difuso que se expressa permanentemente, mas que não é dito em voz alta, simplesmente porque as pessoas têm medo. As pessoas não têm vontade de se expor porque elas têm medo". (Representante eleito do CE, SUD).

Nesta empresa, como para muitos trabalhadores, falar de seus problemas de saúde ligados ao trabalho está longe de ser uma evidência (Gollac e Volkoff, 2006). Assim como em outras profissões encaradas como vocação, como a dos dançarinos (Sorginet, 2004, 2006, 2012) ou dos médicos (Lapeyre, Robelet, 2007), as profissões de engenheiros e pesquisadores implicam importantes investimentos, feitos em nome das satisfações e gratificações simbólicas que estas atividades oferecem (Marry e Jonas, 2005; Darbus e Jedlicki, 2014). Se recursos importantes são necessários para manter-se saudável (Baudelot e Gollac, 2003), estas características alimentam igualmente a invisibilidade das penibilidades deste trabalho. $\mathrm{O}$ engajamento sem limites faz parte de uma ética profissional que conduz engenheiros e pesquisadores a aceitarem este sofrimento e a minimizá-lo: aqueles que reivindicam uma paixão por suas atividades dificilmente admitem as penas que decorrem de seu superengajamento (Goussard, 2017) e invocam um ethos profissional próximo do "heroísmo científico" observado entre os pesquisadores diante dos perigos das substâncias radioativas que manipulam (Fellinger, 2010). Observamos também que para os trabalhadores deste centro de Pesquisa e Desenvolvimento (P\&D) formados em estabelecimentos de prestígio do ensino superior, como o Politécnico, Central, Supélec ou Supaéro, a invisibilidade das penas parece menos ligada à vocação do que à socialização do autocontrole, da capacidade de conter suas emoções e comprovar ser resistente no trabalho. Esta proximidade com os valores de excelência e performance é vista já em seu percurso escolar. Durante sua formação superior, aprenderam não somente 
a se considerar elite, mas interiorizaram as normas de um trabalho intensivo e de exigências temporais extensas (Bourdieu, 1989; Rochex, 1991; Darmon, 2013). Neste momento constituíram também uma hexis particular, feita de segurança e autoconfiança (Darmon, 2013) que, assim como entre diplomatas (Loriol, 2010) e profissionais das finanças (Bousssard et Dujarier, 2014), traduz-se por uma capacidade de tomar distância das emoções e pela contenção das penibilidades do trabalho. Especialmente desde sua implantação neste centro de pesquisa, a organização por projeto prolonga os efeitos desta socialização de valores como a competição e a superação dos próprios limites: ela instaura um mercado de trabalho de concorrência interna que implica, para os empregados, a obrigação de manter uma boa imagem junto a gerentes e chefes de projeto, mostrando-se "brilhantes", "combativos" e "performáticos", para retomar os termos nativos utilizados, afim de serem escolhidos para integrar os projetos mais valorizados, cujas equipes são recompostas, em média, a cada três anos. Assim como nas profissões superiores regidas pelo conceito de "up or out" (Boni-Le Goff, 2010; Thine, 2007; Stenger, 2015), que consiste em promover apenas os empregados mais ajustados às normas comportamentais da empresa e a excluir definitivamente aqueles que não se enquadram, as dúvidas, fraquezas e dificuldades devem permanecer, tanto quanto possível, fora de vista.

Ainda que discreto e silencioso, esse aumento das manifestações de mal-estar reflete os suicídios de trabalhadores ocorridos durante os anos 2000 dentro do grupo, como em outras grandes empresas francesas como Renault, La Poste e France Télécom. Também repercute na crescente preocupação das centrais e federações sindicais em relação à saúde dos trabalhadores para fomentar a construção progressiva do tema como ação sindical neste centro de $\mathrm{P} \& \mathrm{D}$ onde engenheiros, executivos e pesquisadores alimentam, no entanto, por sua autocensura, a invisibilidade das penibilidades de seu trabalho. 


\section{AS CONCEPÇÕES MILITANTES DAS PENIBILIDADES NO TRABALHO: DO MULTI-POSICIONAMENTO AO CON- SENSO ANUNCIADO}

Durante os anos 2000, os agravos causados pelo trabalho surgem como uma questão sindical central no centro de pesquisa estudado. Esta segunda parte do artigo dedica-se a compreender como foram construídas, no espaço de uma década, as concepções ativistas sobre o assunto. Veremos que estas foram configuradas tanto pelas reivindicações sindicais (2.1.), quanto pelas experiências profissionais dos ativistas (2.2.) para chegarem, apesar da heterogeneidade dos posicionamentos, a um consenso intersindical apresentado em torno do questionamento da organização do trabalho (2.3.).

\subsection{Concepções locais espelhadas nas linhas sindicais?}

Se é verdade que as solicitações dos trabalhadores em sofrimento tiveram papel importante na estruturação das ações sindicais em matéria de saúde no trabalho do ponto de vista local, as maneiras de encarar o tema são fruto também da política desenvolvida nas instâncias nacionais. Ora, sobre este ponto, todas testemunham uma crescente sensibilidade a respeito deste fenômeno (Goussard, 2012; Goussard e Tiffon, 2017b); desde as organizações que no passado mostraram-se mais relutantes à ideia de investir no assunto, até aquelas que se mostraram favoráveis a ele desde os anos 70 (Linhart, Linharte Malan, 1998). Apesar do interesse compartilhado, os posicionamentos divergem, no entanto, entre as confederações, em função dos corpus teóricos mobilizados. Enquanto que a CFE - CGC aborda a questão a partir da noção de stress, a CFDT se mostra mais convencida pelas abordagens sociológicas do trabalho e das organizações (Delmas, 2011). A união sindical SUD privilegia, por sua vez, os ensinamentos obtidos nas lutas locais para construir seu repertório de ação, ao mesmo tempo que os compara a pesquisas acadêmicas de sociólogos do trabalho, sem reivindicar, no entanto, "levantar bandeiras", a não ser para situar-se do lado "dos interesses 
dos trabalhadores" (Beynel, 2017). Observamos também mudanças paradigmáticas no seio de certas centrais como a CGT, cuja "estratégia de trabalho" é fortemente marcada pela clínica da atividade, a ergonomia e a ergologia no período 2008-2016 (Fortino, 2017), enquanto mostrava-se bastante influenciada pela psicodinâmica do trabalho durante a década precedente (Delmas, 2011).

À luz destas influências teóricas contrastantes, as centrais chamam os ativistas para variadas modalidades de ação em campo. Neste sentido, a CFE-CGC preconiza a implementação de práticas de inspiração médica e psicológica como os cursos para gestão do stress, os grupos de vigília ou de escuta psicológica, e busca quantificar a dimensão do fenômeno através de ferramentas de medição. Mobilizando por vezes um registro de denúncia, identifica-se mais com uma abordagem de apoio ao planejamento dos modos de gestão da atividade, pois não abre debate sobre as questões e finalidades do trabalho, como o fazem reconhecidamente a CFDT, a CGT e a união sindical Solidários. Recusando-se a fazer da penibilidade no trabalho um problema individual, estas instâncias nacionais pretendem questionar seus fundamentos estratégicos, organizacionais e administrativos, a fim de expor as condições sociais e as lógicas coletivas que o regulam (Goussard e Mias, 2014).

No centro de pesquisa estudado, estas orientações confederais alimentam as práticas de alguns ativistas. Os representantes da CGT e do SUD, por exemplo, explicam quase que sistematicamente as situações de mal-estar através das transformações institucionais, organizacionais e administrativas que afetaram e afetam seu serviço há mais de 15 anos, e que entram em contradição com os valores do serviço público aos quais são fortemente apegados.

"Não havendo nenhuma espécie de acompanhamento das privatizações, como têm algumas organizações sindicais tradicionais da empresa, sempre declaramos aos trabalhadores que aceitar a privatização era aceitar a catástrofe e que depois das privatizações teríamos reorganizações, que o trabalho das pessoas seria profundamente reorganizado e que isso causaria sofrimento. E olha que 
não nos enganamos muito neste quesito. Na SUD, estávamos todos muito interessados pelo assunto, mais próximos de uma abordagem sobre a subjetividade no trabalho do que outras organizações, onde não é da cultura deles este viés. Então, essa questão sempre nos tocou e organizamos reuniões sobre o tema. Convidamos pessoas para palestrar. Convidamos, sobretudo, sociólogos. Nos interessamos pelo trabalho de Dejours, conhecíamos o trabalho de Hirigoyen. Estes assuntos circulavam entre nós. Entre os Solidários e nós, aqui no P\&D. Então, nós lutamos contra a tendência de considerar que estes problemas simplesmente não existem ou que estão sujeitos à subjetividade dos trabalhadores e nós, nosso grande objetivo, é criticar a organização do trabalho e agir sobre a organização do trabalho" (representante eleito junto à CE, SUD).

Sabemos, no entanto, que o posicionamento das organizações sindicais pode divergir em função das esferas confederais, federais e locais (Giraud, 2009; Piotet, 2009). Observamos, de fato, que alguns ativistas oscilam entre representações de acordo com as palavras de ordem das confederações e outros encontram-se em oposição a elas. Assim acontece com um pesquisador, eleito, filiado à CGT, que milita por levar em conta a organização do trabalho para a compreensão dos riscos psicossociais, enquanto defende, em outras ocasiões, um discurso naturalizante e individualizante com respeito a estes riscos: "Temos uma profissão exigente, mas sentimos prazer ao exercê-la e o perigo está também nesse ponto, pois nos acostumamos com a grana. Então as pessoas precisam se proteger de si mesmas. É preciso dizer não, recusar as tarefas suplementares e também aceitar não estar em todos os lugares, não ter controle sobre tudo. Além disso, existe uma discriminação real entre os indivíduos, segundo suas capacidades físicas. Meu chefe de grupo, por exemplo, trabalha em torno de 60 horas por semana e agüenta. Ele tem um físico de ferro (...). Deste modo, é responsabilidade de cada um, também, ter consciência dos seus limites. E mesmo que não seja dito em voz alta, são as pessoas que fazem as escolhas, ou o meio familiar que acaba amortecendo as consequências. É assim que as coisas acontecem, na realidade." 
Notamos, igualmente, diferenças entre as reflexões da CFDT enquanto confederação e o posicionamento de um ativista local. Interrogado sobre as reivindicações de sua organização sindical relativas a stress e penibilidade no trabalho, responde que trata-se de uma realidade específica dos executivos e que inclusive a remuneração das horas extras constitui uma demanda chave sobre o assunto.

"Para os trabalhadores e os técnicos, não há sofrimento moral, mas para os executivos sim. Há ainda mais exigências sobre eles. São mais exigidos no trabalho, nos resultados e nas horas trabalhadas. E o problema não é que eles não registram suas horas, mas que não sejam remuneradas as horas extras. Há muitos que nem tiram férias. E fazem isso voluntariamente. Não são obrigados, enfim, pelo menos espero que não. Então remunerar suas horas extras e as férias acumuladas, seria uma forma de reconhecimento do seu trabalho."

Enfim, podemos igualmente apontar discordâncias entre as representações individualizantes veiculadas pela CFE-CGC na esfera nacional e o posicionamento de alguns ativistas locais, que oscilam entre uma leitura antagonista entre os interesses dos trabalhadores e a direção, e a tentativa de reaproximação dos pontos de vista.

"É preciso manter a pressão sobre a direção, colocá-la face a face com suas responsabilidades mostrando que é a única responsável pela desmotivação e a exaustão dos trabalhadores. (...) Reduzir os custos diminuindo o número de empregados enquanto mantém, ou até aumenta, a carga de trabalho é uma armadilha a curto-prazo (...) que não beneficia nem a empresa e nem, é claro, os trabalhadores".

Se a atenção permanente, da qual fazem prova as centrais sindicais a respeito da temática da saúde no trabalho, constitui certamente um motivo de engajamento sobre o assunto para numerosos militantes locais, a maneira como estes se reconhecem no plano tanto conceitual quanto prático depende também de suas trajetórias e experiências profissionais. 


\subsection{Reflexões sindicais na esteira das experiências profissionais dolorosas dos ativistas}

O engajamento sindical nunca está desconectado das preocupações políticas e pessoais dos ativistas, elas mesmas sendo fruto das trajetórias sociais, escolares e profissionais de cada um (Guillaume e Pochic, 2009). No centro de pesquisa estudado, observamos que estas trajetórias têm papel fundamental também na maneira de encarar as questões de saúde no trabalho, como pensá-las e explicá-las. O fato de ter sofrido pessoalmente um episódio de mal-estar no trabalho constitui, aliás, quase que sistematicamente, uma razão para engajar-se nesta área de reivindicação. É o caso de Daniel, ativista da CFE-CGC fortemente envolvido nas atividades da comissão de acompanhamento dos riscos psicossociais (RPS) dentro do CE. Diplomado em uma escola de engenharia no início dos anos 80 , integrou rapidamente o centro de pesquisa como chefe de laboratório. Ele fala dos dez primeiros anos de sua carreira como uma época particularmente estimulante: "tínhamos dinheiro, meios para trabalhar, tínhamos trabalho demais e não de menos (...). Mas não estávamos estressados como hoje", tendo "a sorte de trabalhar com bons gerentes", "chefes vindos da área técnica, de alto nível”. Desejoso de ganhar mais responsabilidades, ele deixa seu departamento para integrar um novo e assume o posto de chefe de equipe junto a 20 trabalhadores. A atividade técnica não é mais a mesma, mas ele tem prazer em descobrir esse novo universo profissional. Seus superiores, no entanto, o advertem sobre algo que parece essencial: “o acordo era de me darem o emprego, mas que depois eles não ouvissem mais falar de mim. Quando se é gerente, não se deve relatar coisas negativas. Não se deve apontar os problemas, as dificuldades. Não se deve fazer barulho." Daniel toma nota desta diretriz, adaptase aos poucos a suas novas funções e rapidamente sente-se realizado na nova atividade. Com o passar do tempo, em dez anos sua equipe aumenta, acolhendo aproximadamente 50 trabalhadores. Também é levado a assumir novas responsabilidades, como a segurança do laboratório. Descobre então que certos procedimentos não estão sendo 
aplicados corretamente pelos prestadores de serviço do laboratório sob sua tutela. Ele tenta fazer cumprir as regras, mas confronta-se com a resistência dos trabalhadores subcontratados e sobretudo de seus superiores. Procurando uma solução junto a seus próprios gerentes, novamente enfrenta o silêncio: "ninguém queria assumir as questões de segurança, mas tivemos dois acidentes e havia risco de morte, então eu insisti e a partir deste momento ganhei a antipatia do meu chefe." Com seus alertas repetitivos, Daniel quebrou o acordo tácito segundo o qual "quando se é gerente, não se deve fazer onda".

Foi o início dos problemas. "O chefe de departamento começou a me assediar, minimizando sistematicamente meus resultados. Tudo o que eu fazia era desvalorizado. (...) Um dia ele até me disse que eu era um trabalhador temporário do espetáculo". Para tentar satisfazer seu superior provando seu profissionalismo, começou a trabalhar mais, no escritório, em casa, durante as férias. Suas jornadas começavam freqüentemente às $5 \mathrm{~h}$ da manhã para terminar por volta das $18 \mathrm{~h}$. Daniel trabalhava em torno de 70 a 80 horas por semana. Apesar disso, a confiança de seu superior acabou e este lhe pede para deixar o serviço. Este pedido extremamente brutal se traduz em palpitações, que o levam a consultar um cardiologista. O diagnóstico é definitivo. Daniel sofre de sobrecarga e de depressão ligada ao trabalho. O médico lhe prescreve uma licença de seis meses.

Em sua volta ao centro de pesquisa, tem alguém sentado em sua poltrona e responsável por suas missões. Daniel encontra-se então sem atividade, nem escritório durante duas semanas que lhe parecem intermináveis. Decide então aproximar-se de um sindicato, para assegurar sua defesa e encontrar apoio. Convencido da importância da iniciativa, torna-se rapidamente delegado sindical na CFE-CGC, representante da categoria no CE e logo assume responsabilidades dentro da organização. Paralelamente, processa seu superior criminalmente por assédio moral; processo que ele ganha dois anos mais tarde, recebendo assim o reconhecimento do abuso sofrido. Em suas atividades sindicais, Daniel se diz muito dedicado à causa da saúde no trabalho. 
A exemplo da experiência dolorosa que ele mesmo viveu, foca quase que sistematicamente na atitude dos administradores para explicar as dificuldades expressas pelos trabalhadores que buscam sua ajuda.

"Entre as pessoas à beira do precipício, há muitos casos que se repetem o tempo todo. Encontramos pessoas que não têm o que fazer porque seus chefes só aproveitam $20 \%$ de sua capacidade. Outra causa de mal-estar é a opacidade no processo de promoções. São pessoas que não sabem o que seus chefes pensam delas, a quem ninguém diz nada, mas que são repreendidas o tempo todo. Ou quando grupos de trabalho que funcionavam muito bem são extintos pelos administradores, sem explicação, sem nenhuma justificativa. Estas situações também podem estar ligadas a administradores sem competências de RH e que possuem um comportamento infernal."

Uma leitura análoga pode ser feita sobre o posicionamento sindical de Céline. Detentora de um diploma DUT (Diploma Universitário Tecnológico) de medidas físicas nos anos 90, ela integrou o centro de pesquisa como técnica de testes poucos meses após ser diplomada. Durante os dez primeiros anos de sua carreira, trocou regularmente de equipe para descobrir novos horizontes técnicos de acordo com suas mudanças. Reconhecida por seus superiores por suas competências profissionais e seu desejo de progredir, lhe foi oferecida a direção de uma pequena equipe, com a possibilidade de uma promoção a executiva. Durante dois anos, ele exerceu tal função de administradora sem, entretanto, ter o estatuto do cargo.

Ao questionar seus superiores sobre a possível promoção, estes lhe respondem que vai demorar, que seu caso foi, infelizmente, esquecido e que as cotas de promoção já foram ocupadas. Céline lida muito mal com a situação, que ela interpreta como uma falta de consideração com seu trabalho e dedicação de todos esses anos. Decepcionada, pede demissão de sua função de administradora para reassumir um cargo técnico. Finalmente, depois de dois anos, receberá a promoção, mas jamais exercerá a função de administradora, uma vez que a experiência passada foi muito dolorosa para ela. 
Quando seu segundo filho nasceu, passou para jornada parcial (28 horas por semana) a fim de tentar conciliar da melhor maneira sua família e seu trabalho. Percebeu rapidamente que este arranjo não produziu os efeitos esperados. Sua carga de trabalho permanecendo a mesma, é obrigada a trabalhar em casa nas quartas-feiras, paralelamente aos cuidados com as crianças. Do mesmo modo, viu-se obrigada a estender suas jornadas no escritório durante os outros quatro dias da semana, para cumprir seus prazos. Às vezes trabalha à noite e nos finais de semana para recuperar o atraso, no entanto recebe reclamações regulares por parte dos colegas, que acham que ela não está suficientemente presente no escritório. Contrariada pela situação e sentindo-se culpada por não conseguir manter seus compromissos, tem dificuldades de dormir e começa a sofrer de uma enorme fadiga.

"Começaram a reclamar da minha ausência nas reuniões de quartas-feiras, da minha demora em responder e-mails, de eu dizer não quando me propunham missões. Então me culpava por dizer não sistematicamente, por não poder responder às urgências. E também me sentia estressada pois percebia que não poderia evoluir como os outros e me sentia culpada em casa de voltar tão tarde quando estava no trabalho, e de trabalhar nas quartas quando tinha decidido me dedicar às crianças neste dia. E com o tempo, acabam não te propondo mais projetos interessantes (...). É um problema real, para um executivo, passar para a jornada parcial. Isso não se faz mais. As pessoas que trabalham 28 horas não são reconhecidas, de jeito nenhum. (...) Eu não agüentava mais. Estava muito, muito, muito cansada e o tempo todo sob pressão."

Em busca de apoio, aproximou-se de vários ativistas sindicais e decidiu assumir um mandato no CHST, enquanto eleita do CFECGC. Esta missão tinha para ela um sentido especial: "todos estes assuntos me tocam e eu conheço muito bem a questão da falta de reconhecimento". Enquanto Daniel tem tendência a explicar o sofrimento no trabalho através da violência de certos administradores, a chave de leitura de Céline é mais voltada para a sobrecarga de 
trabalho, a falta de reconhecimento e os problemas com planos de carreira, três questões que foram problemáticas em algum momento de sua própria trajetória profissional.

"As manifestações de stress são bastante freqüentes e eu diria que isso não me espanta nem um pouco, pois sempre se exige mais dos agentes, com equipes cada vez menores, então obviamente que haverá sobrecarga de trabalho (...). Nossa jornada de trabalho não está adaptada à carga de trabalho que nos é exigida. Para os técnicos, a preocupação maior é quanto ao fechamento dos laboratórios. Eles se perguntam em que tipo de molho serão "servidos". Mas, para os executivos, sim, é mais uma questão de sobrecarga. Muito trabalho o tempo todo e sempre com urgência, sem receber o reconhecimento merecido. E também tem a ver com o plano de carreira, com as carreiras estagnadas, as promoções que demoram anos".

Se em alguns universos profissionais, as identidades de profissão moldam as representações sindicais do stress ou dos riscos psicossociais (Loriol, 2012; 2017), notamos que estas também podem estar ligadas às experiências profissionais dolorosas de cada um e, inclusive, à decepção de suas esperanças de valorização no trabalho.

Vejamos agora como estas sensibilidades e interpretações heterogêneas se expressam no seio da comissão intersindical de acompanhamento dos riscos psicossociais (RPS) do CE.

\subsection{Sofrimento, saúde, organização do trabalho: a evolução do registro conceitual intersindical no seio da comissão de acom- panhamento dos riscos psicossociais}

Apesar da heterogeneidade dos posicionamentos sindicais em matéria de saúde no trabalho observados nesta empresa, o que se sobrepõe, sobretudo dentro da comissão interna do CE, é a vontade de ultrapassar as divergências de pontos de vista para fazer emergir uma postura comum e apresentá-la como tal à direção, contra a qual as batalhas acontecem. 
"Não devemos nos enganar de inimigo, estamos todos conscientes." (Eleito do CE e do CHST, SUD)

"Não estamos sempre de acordo, mas sabemos muito bem que o adversário é a direção. Devemos manter juntos a pressão sobre ela." (Eleito do CE e representante no DP, CFE-CGC)

É sob esta perspectiva que no momento da criação desta comissão, no final dos anos 2000, os eleitos solicitam uma equipe de psicólogos do trabalho para assisti-los em suas missões. Em seguida, encomendam a estes psicólogos um estudo sobre o sofrimento no trabalho dos assalariados do centro. A referência à psicodinâmica do trabalho está muito presente, seja nos discursos e representações dos eleitos, seja nos quadros teóricos mobilizados pelos profissionais da equipe. Um ano após a entrega de relatório comprovando tais fenômenos, os eleitos encomendaram novo estudo à uma equipe de sociólogos do trabalho, da qual faço parte. Segundo sua demanda, tratava-se desta vez de examinar as ligações entre as reformas organizacionais do centro e a vivências dos trabalhadores. Seguiuse, então, uma segunda pesquisa, focada na quantificação de trabalhadores afetados por problemas de saúde ligados ao trabalho e, em seguida, uma terceira pesquisa, sobre a aceleração dos ritmos de trabalho e as situações dispersivas (Datchary, 2012) às quais os pesquisadores são submetidos.

No espaço de uma década, a posição dos membros da comissão de acompanhamento dos RPS evoluiu progressivamente de uma postura de denúncia do sofrimento no trabalho, fenômeno amplamente desprezado durante os anos 2000, para uma reflexão sobre seus incitadores organizacionais, como explica um dos representantes: "Estamos de acordo sobre o assunto. Sobre o fato de que não podemos tratar este problema sem refletir sobre a organização do trabalho. Alinhamos nossas ideias. Depois do primeiro estudo." (eleito do CE, SUD). Aliás, neste sentido, a comissão foi rebatizada há alguns anos de "comissão de saúde e organização do trabalho". Se durante os encontros regulares entre os eleitos desta comissão as divergências de pontos de vista são palpáveis, diante da direção e 
no seio das instâncias, todos procuram se expressar em uma só voz, sem necessariamente, deixar aparecer os elementos de discórdia e os códigos de leitura de cada um sobre a penibilidade no trabalho.

\section{AGIR SINDICALMENTE EM NOME DA SAÚDE DOS TRA- BALHADORES: TENTATIVAS, VITÓRIAS E OBSTÁCULOS}

O que produzem as concepções sindicais em matéria de saúde no trabalho, uma vez postas em ação? Para responder a esta questão, o foco será direcionado para dois espaços chaves da intervenção sindical em matéria de defesa da saúde dos trabalhadores: os grupos multidisciplinares onde são analisados os casos individuais (3.1.) e as instâncias de negociação, onde estas questões são encaradas do ponto de vista do coletivo (3.2.). Nestes dois casos, as ações militantes dão lugar a um balanço morno, uma vez que o debate sobre a organização do trabalho dificilmente se estabelece com a diretoria de forma verdadeira.

\subsection{A gestão dos casos individuais: um horizonte bloqueado?}

Um acordo sobre a prevenção e o aprimoramento da qualidade de vida no trabalho foi assinado em 2010 dentro do grupo ao qual pertence o centro de pesquisa estudado. Seu impacto local implica na implantação de diferentes medidas, como o reforço dos grupos multidisciplinares iniciados em 2006, levando em conta a situação dos trabalhadores que se declaram em sofrimento. Segundo os casos examinados, diferentes agentes podem ser mobilizados: os que trabalham na prevenção, médicos do trabalho, assistentes sociais, enfermeiros, chefes de projeto. Os representantes das organizações sindicais, os administradores e os membros do RH são, por sua vez, sistematicamente solicitados.

Ativistas sindicais possuem um olhar contraditório sobre estes grupos de trabalho. Por um lado, tais grupos constituem uma oportunidade de adquirir novas competências, especialmente através do contato com profissionais de saúde, e de avançar coletivamen- 
te sobre um assunto sobre o qual ainda têm dificuldades de encarar a si mesmos como dotados de legitimidade para falar.

"Nós não temos função médica, uma vez que não somos nem psicólogos nem médicos. Então, quando tenho diante de mim alguém que não está bem, apelo para o corpo médico através dos grupos multidisciplinares, porque se eu não fizer nada e a pessoa se mata, a responsabilidade é minha. E temos casos assim aqui. Já aconteceu comigo. Por razões profissionais. Então precisamos estar na escuta e encaminhar aos médicos quando os agentes estão à beira do precipício." (Eleito do CE, representante no DP, CFE-CGC)

O objetivo é também oferecer um espaço de diálogo aos trabalhadores afetados a fim de fazê-los entender que seu caso não é um caso isolado, esclarecendo que eles não têm nem culpa nem responsabilidade sobre a situação. Trata-se de difundir outros tipos de concepção sobre penibilidade, diferentes das concepções de inspiração higienistas, médicas e individualizantes, geralmente veiculadas por outros membros dos grupos multidisciplinares. Este trabalho de desconstrução é, contudo, espinhoso. Ativistas insistem sobre o fato de que os trabalhadores assistidos por esses grupos recebem sistematicamente propostas de solução que não questionam os fundamentos coletivos de sua situação. Seja com licenças médicas, conselhos para melhorar hábitos de vida, aulas de coaching, cursos de gestão do tempo ou do stress, o procedimento sempre visa delegar aos indivíduos a gestão de suas dificuldades, o que contribui, de fato, a torná-los responsáveis por elas. Além disso, ativistas observam que as situações gerenciais conflituosas se resolvem, na maior parte das vezes, com uma proposta de transferência dos trabalhadores. Se esta solução responde à necessidade imediata de "retirar os trabalhadores que estão à beira do precipício dos ambientes que os deixam doentes" (eleito do CE e do CHSCT, CGT), ela revela todas as dificuldades encontradas pelos ativistas para agir na linha gerencial. 
"Freqüentemente, a política dos grupos multidisciplinares é que se alguma coisa não está bem com alguém, esse alguém deve partir. Se não, é porque a pessoa não tem dinamismo. Permanecer num cargo onde as coisas não estão funcionando, não é lógico então, é preciso partir. E dai entramos numa espiral terrivel. Porque a saída é escapar de um conflito ou de um cargo onde não estamos bem. É terrivel, porque quando uma pessoa entra em conflito declarado contra seus superiores, a pessoa morre. Quando digo morte é porque se alguém diz que as coisas não estão bem, acabou. Será sua responsabilidade organizar sua transferência. E ele ou ela vão ter muitos problemas até finalmente partir. Então não existe possibilidade de reparação. Aqui, enquanto as coisas vão bem, tudo bem. Mas se um conflito surge, aí, a saída é alguém ir embora e, obviamente, são os agentes que devem sair, não os administradores. Não temos poder de ação sobre a estrutura hierárquica ou o mandato de um chefe de grupo que faz seus agentes sofrerem. Existe cooptação e solidariedade entre os administradores, com os quais não podemos mexer." (Eleito do CE, SUD)

"Existe um caso que se arrasta há dois anos em um dos grupos. Nos demos conta que a metade dos caras sofria por causa de uma chefe de grupo infernal, uma jovem ambiciosa, que rebaixa os agentes em suas competências técnicas e que usa os resultados dos trabalhos deles para se auto promover. Montamos o caso entre os grupos disciplinares, mas a resposta do diretor foi que ele entendia a questão, mas não havia nenhum elemento factual que pudesse validar a transferência da dita chefe. Era isso. Faz dois anos que o caso se arrasta. As pessoas esperam que ela vá embora. Mas se ela for promovida a chefe de departamento, já avisamos o RH, que vamos usar artilharia pesada." (Eleito do CE e do DP, CFE-CGC)

Os ativistas também lamentam o fato de que as causas organizacionais da penibilidade no trabalho não sejam de fato abordadas nos grupos multidisciplinares. Como declara um deles: "sobre a organização do trabalho, nos sentimos terrivelmente impotentes. 
Não damos conta. Mesmo nos casos mais difíceis. Não conseguimos nenhum tipo de mudança a esse respeito". (eleito do CE, CGT). Nas instâncias de negociação, por sua vez, e especialmente no CE, esta temática é objeto de debates relativamente freqüentes. Observemos agora como os ativistas buscam orientá-los e ter poder sobre as decisões da direção quando se trata deste assunto.

\subsection{Nas instâncias de negociação: "manter a pressão" apesar do status quo}

A participação em três estudos encomendados pela comissão de acompanhamento dos RPS permitiu acompanhar o desenrolar dos debates sobre a penibilidade do trabalho dentro de várias sessões do CE entre 2013 e 2017. A cada vez, tratava-se de apresentar os resultados dos estudos realizados e participar dos debates com a direção e os representantes das categorias sobre as questões de saúde no trabalho. Dois eixos principais podem ser apontados no decorrer das controvérsias.

\subsubsection{Lutar contra a subestimação do mal-estar: a batalha dos números}

O primeiro diz respeito ao reconhecimento dos problemas de saúde no centro de pesquisa, fenômeno ainda amplamente ocultado no início dos anos 2000 e que, para os ativistas, era questão de trazer à luz, através do estudo realizado pela equipe de psicólogos do trabalho e da primeira das pesquisas das quais participei. Estas pesquisas, baseadas em materiais quantitativos (dois grupos de trabalho de 11 e 19 pessoas reunidas três vezes durante três horas no caso do primeiro; 10 dias de observação e 70 entrevistas a partir de uma amostragem representativa da população do centro no caso da segunda) tiveram como traço comum esclarecer os efeitos sanitários da penibilidade do trabalho neste centro de pesquisa, levando em conta as trajetórias profissionais do trabalhadores afetados e das causas organizacionais desta penibilidade. Diante da apresentação dos 
resultados desses estudos durante as assembléias do $\mathrm{CE}$, a direção apresenta um primeiro contra-argumento: ela duvida da representatividade das amostragens das pesquisas e acusa os representantes das categorias de terem direcionado os estudos colocando os pesquisadores em contato com os trabalhadores em sofrimento, a fim de alimentar suas próprias reivindicações a respeito do tema.

"Este documento, numa primeira leitura, reforça dificuldades que podemos encontrar em alguns casos, mas não traduz a situação da maioria dos agentes." (Proposta do DRH, processo verbal de uma das sessões do CE)

Os representantes das categorias refutam essa crítica por duas vezes e acusam publicamente a direção de irresponsabilidade e de negação do sofrimento. Muitos sublinham, igualmente, a convergência entre os resultados destes estudos e as constatações defendidas pelos ativistas depois de anos.

"Esta pesquisa traz alguns esclarecimentos que confirmam as propostas defendidas pelos eleitos dentro do CE. Ela chama atenção para a extensão de certos fenômenos que podem ter sido subestimados no passado, especialmente, em relação à carga de trabalho." (Eleito do CE, CGT)

"Este estudo confirma alguns pontos aos quais os eleitos se dedicam há anos, tentando trazê-los ao debate. A prova apresentada indica que é o trabalho que deve ser tratado, e não os trabalhadores." (Eleito do CE, SUD)

A responsável pelos recursos humanos responde que não está negando os fatos e que, ao contrário, está "consciente de que certas coisas podem ser melhoradas". Encerra, no entanto, o debate lembrando que "os agentes que sofrem cada vez mais com dificuldades não são, felizmente, a maioria.” Ao final de uma dessas assembléias, os ativistas decidem então encomendar um novo estudo, apoiado nos 
métodos quantitativos, a fim de medir a extensão do fenômeno e responder às objeções da direção. Em princípio, a direção se opôs à difusão deste questionário, que considerava muito focado nos problemas de saúde no trabalho. Os representantes das categorias apelam para um advogado, que fornece os argumentos necessários para fazer circular, apesar de tudo, o questionário. Após vários meses de discussão, um link é enviado por e-mail aos 2000 trabalhadores do centro de pesquisa para que estes possam preenchê-lo. Aproximadamente 1100 respondem, atingindo a taxa de $51 \%$ de retorno. A amostragem se revela, então, representativa da população em diversos pontos: a distribuição por idade, sexo e lotação dos participantes confere com as características da população do centro indicadas no balanço social. Este questionário mostra que mais de um terço dos trabalhadores do centro declaram que tem ou tiveram problemas de saúde ligados ao trabalho. Entre os afetados, um a cada dois declara ter problemas de sono, $72 \%$ apresentam sinais de fadiga e esgotamento, $42 \%$ apresentam dor de cabeça ou enxaquecas, 58\% sinais de nervosismo e ansiedade, $21,5 \%$ palpitações e quedas de pressão, perto de um terço mencionaram dores de estômago, cólicas, úlceras, um em cada cinco tem ou teve doenças dermatológicas e $60 \%$ declararam sofrer de contraturas, dor nas costas ou dores na coluna por causa do trabalho. Por fim o questionário revelou que $14 \%$ dos trabalhadores consultam um terapeuta devido a estas dificuldades.

Durante a assembleia de apresentação desses resultados aos membros do CE em 2015, o diretor do centro de pesquisa compartilhou seu "desconforto" quanto às taxas de resposta a este estudo (51\%): "podemos realmente deduzir que ele é representativo?". Ele acrescenta ter “dúvidas" em relação a "certos resultados no mínimo espantosos. Por exemplo, $36 \%$ dos agentes declarou ter sofrido de problemas de saúde; um resultado mais que espantoso. Mais surpreendente ainda, $70 \%$ dos executivos da diretoria teriam sofrido de problemas de saúde.”. Declara que os conhece pessoalmente e que nunca teve conhecimento de seus eventuais problemas de saúde. Conclui afirmando que "não saberia o que é possível concluir com tal enquete" e exorta os representantes das categorias a adotarem 
"grande prudência" no uso que fariam deste estudo junto aos trabalhadores do centro. Aqueles entram em conflito com a equipe da direção sobre a representatividade dos resultados. O diretor conclui lembrando dos números estabelecidos pelos serviços da medicina do trabalho: somente 150 trabalhadores teriam apresentado problemas de saúde no trabalho no corrente ano, ou seja 6\% e não 36\% dos trabalhadores como mostrava o questionário. $\mathrm{O}$ secretário do $\mathrm{CE}$ aponta que, mais uma vez, a Direção tenta minimizar ou subestimar os problemas. Fim da discussão. Próximo assunto.

\subsubsection{Qual "diálogo social" sobre a organização do tra- balho?}

A segunda etapa do tratamento das questões de saúde no trabalho questiona mais diretamente a responsabilidade da direção, já que trata-se de debater as causas organizacionais da penibilidade do trabalho. Nesta área, os diferentes estudos encomendados pela comissão de acompanhamento dos RPS confirmam e complementam as análises feitas pelos representantes eleitos, apontando correspondências entre saúde e organização do trabalho. Durante a assembléia de apresentação destes resultados ao CE em 2014, e depois em 2017, os membros da direção manifestam, mais uma vez, reservas, voltando sistematicamente ao assunto dos números e da objetividade dos dados produzidos. Suas questões são as seguintes: "os trabalhadores estão qualificados para identificar sozinhos a origem de seus problemas de saúde?", “Como verificar que não cometem erros ao relacionar seus problemas com razões profissionais?", "Como isolar as dificuldades profissionais das dificuldades pessoais na análise quando estas seguidamente estão entrelaçadas na vida real?", "Como saber se os trabalhadores não estão falando de problemas de saúde que ocorreram no início de suas carreiras, ou ainda, em outra empresa?". E principalmente "quem nunca experimentou pequenas preocupações profissionais em sua carreira?” Os representantes das categorias respondem a estas objeções lembrando os casos dos executivos estudados nos grupos multidisciplinares e alimentam o deba- 
te defendendo as constatações estabelecidas na enquete. $\mathrm{O}$ diretor do centro responde ter "dificuldades para compreender a relação entre estes casos de burn-out e a apresentação do relatório", associar os dois temas lhe parece "apressado, para dizer o mínimo". Um eleito da CGT responde que "estes casos de burn-out estão, na sua maioria, ligados à organização do trabalho e desta maneira corroboram a problemática de saúde no trabalho revelada pelo estudo". O diretor dos recursos humanos pede a palavra para indicar que não está de acordo com esta afirmação.

Aos poucos os ativistas sindicais encaminham, assim, o debate na direção das considerações organizacionais, lembrando especialmente da redução de funcionários, das transformações organizacionais e administrativas implantadas nos últimos quinze anos e a burocratização do trabalho de pesquisa.

"Os problemas de saúde, prioritariamente, não dizem respeito à personalidade dos indivíduos, mas sim às disfunções organizacionais ou administrativas." (Eleito do CE, CGT)

"A recepção da Direção a este trabalho é preocupante. Faz anos que os eleitos combatem a ideia segundo a qual os problemas estão ligados a falhas individuais deste ou daquele agente. O problema não é cuidar dos agentes, mas cuidar da organização do trabalho! $O$ valor do trabalho realizado não está no número de pessoas interrogadas, mas na abordagem utilizada. O processo em relação à representatividade imposto a este trabalho pela Direção é totalmente injusto. Os 2000 agentes do $P \& D$ não foram interrogados, mas muitos são os que apontam disputas de poder entre chefes de projeto e chefes de grupo, problemas de atribuição entre Departamentos em relação a projetos, e ainda incoerências entre os programas e as direções de pesquisa. Do mesmo modo, o relatório destaca a burocratização do trabalho dos pesquisadores. Nenhum agente dirá o contrário." (Eleito do CE, SUD) 
Três argumentos são especialmente apresentados pela equipe diretiva no intuito de derrubar a demonstração dos representantes das categorias. O primeiro consiste em questionar a neutralidade dos pesquisadores responsáveis pelo estudo, acusando-os de estarem em conivência com os representantes da base.

"Sem questionar o estudo, o diretor sente, na apresentação feita pelos sociólogos, a vontade dos eleitos de passarem certas mensagens à Direção." (Diretor do Centro, trecho do processo verbal de uma das assembléias do CE em 2017).

O segundo argumento visa, por sua vez, transferir a responsabilidade do mal-estar no trabalho para os próprios trabalhadores. Após "comemorar o fato de que os trabalhadores trabalham bastante" (diretor do centro, trecho do processo verbal de uma assembléia do CE em 2017), a equipe diretiva declara que, na verdade, eles o fazem "por paixão", inclusive tendo tendência a "engajarem-se demais em suas atividades, eles mesmos impondo-se restrições". Ela insiste, assim, na responsabilidade dos trabalhadores em relação a seu engajamento excessivo no trabalho, da grande quantidade de horas extras relatadas na enquete e do "trabalho excessivo a domicílio" (Goussard e Tiffon, 2016) que atinge 64\% deles.

Por fim, o último argumento que torna a discussão obsoleta: lhe parece "totalmente irreal" questionar os dispositivos técnico-organizacionais empregados no centro pois "todos os centros de $\mathrm{P} \& \mathrm{D}$ da França e do mundo trabalham em forma de projetos, logo não podemos funcionar de outra maneira." $\mathrm{O}$ diretor dos recursos humanos acrescenta que ele "estaria mentindo se dissesse que a margem de manobra da direção era enorme" sobre o assunto. No mesmo sentido, o diretor acrescenta que hoje "ninguém pode se livrar dos e-mails. Os trabalhadores recebem todos uma grande quantidade de e-mails, é um fato. Mas a cultura evoluiu. Novas ferramentas estão disponíveis. A partir de agora fazem parte do cotidiano das empresas.". Com as reformas técnicas, organizacionais e administrativas do centro sendo apresentadas não como uma escolha da direção, mas como decisões 
impostas a ela, via mecanismos difusos e longínquos de concorrência entre as empresas e de desenvolvimento de técnicas digitais, tornou-se particularmente difícil trazê-las de volta ao debate.

As assembléias observadas terminaram, sistematicamente, da mesma maneira: a direção declarando-se aberta a "manter o diálogo" com as organizações sindicais e a absorver os apontamentos em suas análises. Segundo os ativistas, nenhuma atitude foi tomada neste sentido. Apesar desta constatação, consideram-se satisfeitos por terem conseguido, no espaço de alguns poucos anos, a não somente expor as manifestações sanitárias da penibilidade do trabalho de pesquisa, mas a impor uma reflexão sobre suas causas coletivas, institucionais e organizacionais, dentro do comitê de empresa.

"Conseguimos provocar uma pequena conscientização, no CE especialmente. A direção não é completamente insensivel a nossos argumentos hoje em dia" (Eleito do CE, SUD).

Se a direção se mostra, até o momento, relativamente fechada para a possibilidade de um verdadeiro debate sobre estas questões, os ativistas consideram que é preciso continuar os procedimentos iniciados para "manter a pressão sobre a direção" e continuar "a confrontá-la com suas responsabilidades" (eleito do CE e do DP, CFE-CGC). Muitos deles acreditam que a verdadeira batalha acontece junto aos trabalhadores, para quem é preciso continuar a divulgar esta questão, a fim de que as línguas se soltem, que as situações não sejam mais vividas sob a culpabilização e que mobilizações sobre este assunto possam surgir. Em todo caso, é com esta perspectiva, que os diferentes relatórios encomendados pela comissão de Saúde e Organização do Trabalho foram entregues nas mãos dos 2000 trabalhadores do centro e que debates sobre estes temas são regulamente organizados pelos ativistas em cada uma das instalações desta direção. 


\section{CONCLUSÃO}

Este artigo propunha examinar a construção progressiva da saúde no trabalho como ação sindical no seio de um espaço profissional em contrapartida à concepção dominante de trabalho penoso. Pretendia, igualmente, esclarecer os mecanismos que guiam a elaboração das representações militantes sobre o assunto, e a compreender como são elaboradas, concretamente, ações sindicais sobre estes temas, ao mesmo tempo que identifica os pontos de conflito observados com a política de prevenção conduzida pela direção do estabelecimento. Acontece que a direção promete o "diálogo social" e se diz pronta a repensar suas práticas, porém, em última instância, os relatórios de produção são determinantes dos termos de negociação sobre as questões de saúde no trabalho. Apesar destes obstáculos, os avanços obtidos pelos ativistas não são menos decisivos, tanto em termos de divulgação de uma visão alternativa das concepções higienistas e individualizantes da direção, quanto da criação de uma agenda sobre estas questões dentro das instâncias de negociação.

\section{REFERÊNCIAS}

ANDOlfatTO, D.; LABBÉ, D. Sociologie des syndicats. Paris: La Découverte, Repères, 2011.

BARRIER, J. La science en projets: financements sur projet, autonomie professionnelle et transformations du travail des chercheurs académiques. Sociologie du travail, n 53, pp. 515-536, 2011.

BAUDELOT, M.; GOLLAC. M. (Dir.). Travailler pour être heureux? Paris: La Découverte, 2003.

BEYNEL, E.; GOUSSARD, L.; TIFFON, G. Solidaires et le travail : du terrain à l'action. Entretien avec Eric Beynel, secrétaire général de Solidaires. In: GOUSSARD L. ET TIFFON G. (Dir.). Syndicalisme et santé au travail. Quel renouvellement de la conflictualité au travail? Vulaines-sur-Seine: Le Croquant, 2017.

BONI-LE GOFF, I. Pratiques et identités professionnelles dans le conseil en management en France: entre ethos du service au client et pression du « up or out ». SociologieS. [En ligne], Dossiers, L'essor des métiers du conseil : dynamiques et tensions, mis en ligne le 03 février 2010. URL : http://journals.openedition.org/sociologies/3072 
BOURDIEU, P. La noblesse d'État. Paris: Éditions de Minuit, 1989.

BOUSSARD, V.; DUJARIER, M. A. Les représentations professionnelles en question. Le cas des intermédiaires dans les fusions-acquisitions. Sociologie du travail, $n^{\circ} 56-2$, pp. 182-203, 2014.

BOUSSARD, V.; MARTIN, E.; VÉZINAT, N. La permanence dans le changement? Les usages renouvelés de la « modernisation » des entreprises publiques. Sociétés contemporaines, $n^{\circ}$ 97, pp. 5-23, 2015.

BOUSSARD, V.; MAUGERI, S. (Dir.). Du politique dans les organisations. Sociologie des dispositifs de gestion. Paris: L'Harmattan, 2003.

CLOT, Y. Le travail à cœur. Pour en finir avec les risques psychosociaux. Paris: La Découverte, 2010.

DARBUS, F.; JEDLICKI, F. Folle rationalisation de l'enseignement supérieur et de la recherche. Savoir/Agir, n² 29, pp. 25-34, 2014.

DARMON, M. Classes préparatoires. La fabrique d'une jeunesse dominante. Paris: La Découverte, 2013.

DATCHARY, C. La dispersion au travail. Toulouse: Octarès, 2012.

DEJOURS, D. Souffrance en France. La banalisation de l'injustice sociale. Paris: Seuil, 1998.

DELMAS, C. "Stress" et "souffrance au travail" des cadres : enjeu syndical et médiatique. In: BOUfFARTIGUE, P.; GADEA, C. \& POCHIC, S. (Coord.). Cadres, classes moyennes: vers l'éclatement? Paris: Armand Colin, 2011, pp. 219-227.

FELLINGER, A. Femmes, risques et radioactivité en France. Travail, genre et sociétés, $\mathrm{n}^{\circ} 23$, pp. 147-165, 2010.

FLOCCO, G. Des dominants très dominés. Pourquoi les cadres acceptent leur servitude. Paris: Raisons d'agir, 2015.

FORTINO, S. Invisibilisation de la pénibilité au travail, mixité et rapports de genre. La Nouvelle Revue du Travail, [En ligne], n4 , mis en ligne le 01 mai 2014, URL : http://journals.openedition.org/ nrt/1422; DOI : $10.4000 /$ nrt.1422

FORTINO, S. Transformer le travail ? Les difficultés d'une refonte en profondeur des revendications autour de la santé au travail à la CGT (2008-2016). In: GOUSSARD, L.; TIFFON, G. (Dir.). Syndicalisme et santé au travail. Quel renouvellement de la conflictualité au travail? Vulaines-sur-Seine: Le Croquant, 2017b, pp. 159-179.

GIRAUD, B. Faire la grève. Les conditions d'appropriation de la grève dans les conflits du travail en France. 2009. Thèse (Doctorat de Sciences Politiques), sous la direction de M. Offerlé, Université Paris I. 
GOLLAC, M.; VOLKOFF, S. La santé au travail et ses masques. Les Actes de la Recherche en Sciences Sociales, n 163, pp. 4-17, 2006.

GOUSSARD, L. Travail et santé: un nouveau défi pour les organisations syndicales. Les Mondes du travail, n 11, février, 2012, pp. 43-56, 2012.

GOUSSARD, L. Travailler au péril de sa santé. Censure et autocensure des ingénieurs à l'égard des pénibilités de leur travail. Perspectives interdisciplinaires sur le travail et la santé, n 19-1, pp. 1-25, 2017.

GOUSSARD, L.; MIAS A. Syndicats. In: ZAWIEJA, P. \& GUARNIERI, F. (Dir.). Dictionnaire des risques psychosociaux. Paris: Editions du Seuil, 2014, pp. 773-775.

GOUSSARD, L.; TIFFON, G. Travailler en projets dans la R\&D. Contraintes temporelles et transformations du travail de recherche. Temporalités, $\mathrm{n}^{\circ}$ 18, 2013. URL : http://journals.openedition.org/ temporalites/2578; DOI : 10.4000/temporalites.2578

GOUSSARD, L.; TIFFON, G. Quand le travail déborde... La pénibilité du surtravail à domicile. Le cas des chercheurs de l'industrie énergétique. Travail et Emploi, n 147, pp. 27-52, 2016.

GOUSSARD, L.; TIFFON, G. Le mal de reconnaissance. Travail invisibilisé, travailleurs déstabilisés. In: CLEACH, O; TIFFON, G. (Dir.). Invisibilisations au travail. Des salariés en mal de reconnaissance. Toulouse: Octarès, 2017a.

GOUSSARD, L.; TIFFON, G. (Dir.). Syndicalisme et santé au travail. Quel renouvellement de la conflictualité au travail? Vulaines-sur-Seine: Le Croquant, 2017b.

GUILLAUME, C.; POCHIC, S. Un engagement incongru? Les cadres et le syndicalisme, l'exemple de la CFDT. Revue Française de Sciences Politiques, n०59-3, pp. 535-568, 2009.

HACKETT, E. J. Science as a vocation in the 1990s: the changing Organizational culture of academic science. The journal of higher education, $n^{\circ}$ 61/3, pp. 241-279, 1990.

JOUVENET, M. Profession scientifique et instruments politiques: l'impact du financement "sur projet" dans des laboratoires de nanosciences. Sociologie du travail, $\mathrm{n}^{\circ}$ 53, pp. 234-252, 2011.

LINHART, D.; LINHART, R. \& MALAN, A. Syndicats et organisation du travail: un rendez-vous manqué. Sociologie et sociétés, Vol. 30, $\mathrm{n}^{\circ} 2$, pp. 175-188, 1998.

LORIOL, M. Travail des diplomates et contrôle des émotions. In: CLOT, Y.; LHUILIER, D. Travail et santé. Paris: Erès, 2010, pp. 37-50. 
LORIOL, M. Stress, souffrance et RPS: Constructions profanes, constructions syndicales et constructions expertes. In: GOUSSARD, L.; TIFFON, G. (Dir.). Syndicalisme et santé au travail. Quel renouvellement de la conflictualité au travail? Vulaines-sur-Seine: Le Croquant, 2017.

MARRY, C.; JONAS, I. Chercheuses entre deux passions. L'exemple des biologistes. Travail, genre et sociétes, $\mathrm{n}^{\circ}$ 14, pp. 69-88, 2005.

PIOTET, F. (Dir.). La CGT et la recomposition syndicale. Paris: Presses Universitaires de France, 2009.

ROCHEX J. X. Entre activité et subjectivité: le sens de l'expérience scolaire. 1991. Thèse (Doctorat de Sciences de l'Éducation), Université Paris VIII, Paris.

SORIGNET, P.-E. Être danseuse contemporaine: une carrière "corps et âme". Travail, genre et sociétés, n¹2, pp. 33-53, 2004.

SORIGNET, P.-E. Danser au-delà de la douleur. Actes de la Recherche en Sciences Sociales, $\mathrm{n}^{\circ}$ 163, pp. 46-61. 2006.

SORIGNET, P.-E. Danser. Enquête dans les coulisses d'une vocation. Paris: La Découverte, 2012.

STENGER, S. Pourquoi travaille-t-on dans un cabinet d'audit « Big Four $»$ ? : Fonctions du système « up or out » : contrôle, compétition et prestige social. 2015. Thèse (Doctorat en Sociologie), HEC, Paris.

THINE, S. La règle du « up or out » dans les cabinets de conseil: ressorts et tensions propres à une pratique de sur-sélection. Journée d'étude Nouvelles normes économiques et transformations des structures sociales, CRPS-CSE-CSU, 2007.

TIXIER, P.-E.; MAUCHAMP, N. (Dir.). EDF-GDF, une entreprise publique en mutation. Paris: La Découverte, 2000.

TIXIER, P.-E. (Dir.). Du monopole au marché. Les stratégies de modernisation des entreprises publiques. Paris: La Découverte, 2002. 